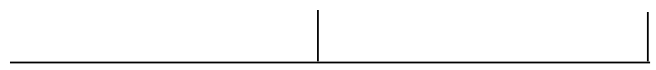

Rev. Latinoam. Psicopat. Fund., São Paulo, v. 13, n. 1, p. 137-139, março 2010

Clínica humanista-fenomenológica: estudos em psicoterapia e psicopatologia crítica

Virgínia Moreira

São Paulo: Annablume, 2009, 254p.

\title{
Clínica humanista-fenomenológica: estudos em psicoterapia e psicopatologia crítica
}

Georges Daniel Janja Bloc Boris

Após a publicação de diversos livros - Mas allá de la persona: hacia una psicoterapia fenomenológica (no Chile, em 2001); Personalidade, ideologia e psicopatologia crítica (com Tod Sloan, em 2002); Mulher feita de azul (de poesias, em 2005); e De Carl Rogers a Merleau-Ponty: a pessoa mundana em psicoterapia (de 2007), Virgínia Moreira lança novo livro: Clínica humanista-fenomenológica: estudos em psicoterapia e psicopatologia crítica, produto da sua experiência e das inquietações como psicoterapeuta humanista e como pesquisadora coerente com sua formação fenomenológica, fundamentada na perspectiva mundana de Merleau-Ponty. A autora foi professora em diversas instituições de ensino superior no Brasil e no Chile, lecionando, atualmente, nos Programas de Pós-Graduação e de Graduação em Psicologia da Universidade de Fortaleza (UNIFOR). 
Sua trajetória, eminentemente crítica, tornou-a pioneira entre seus colegas e parceiros, desde sua dissertação em Educação sobre os Limites da abordagem centrada na pessoa de Carl Rogers, na Universidade Federal do Ceará. Logo depois, voltou-se à tese Para além da pessoa, em que analisou a prática da psicoterapia rogeriana à luz de Merleau-Ponty, no Doutorado em Psicologia Clínica da PUC de São Paulo. Finalmente, pôde enriquecer sua perspectiva fenomenológica sobre a experiência vivida na clínica psicológica a partir da antropologia da experiência, conforme as proposições de Byron Good e de Arthur Kleinman, no pósdoutorado em Antropologia Médica da Harvard Medical School (EUA).

Nos primeiros capítulos de Clínica humanista-fenomenológica: estudos em psicoterapia e psicopatologia crítica, Virgínia Moreira elabora sua proposta de tomar a fenomenologia de Merleau-Ponty como uma importante ferramenta de articulação teórico-prática para a busca do significado da experiência vivida na psicoterapia, na supervisão e na compreensão dos distúrbios psicopatológicos, discutindo historicamente seu trabalho como psicoterapeuta, fruto do humanismo de Carl Rogers e da psicopatologia fenomenológica. Neste sentido, elege os conceitos de empatia, de Rogers, e de mundo vivido (Lebenswelt), de MerleauPonty, como os fundamentos de seu trabalho, além de outras "técnicas" de intervenção clínica: a intuição eidética, a redução, a descrição, a fala autêntica e o ver e ouvir fenomenológicos, sempre considerando a atuação do psicoterapeuta como ser mundano. Assim, sua proposta de compreensão da psicopatologia, fundamentada na perspectiva merleau-pontyana, é sempre concebida a partir dos múltiplos contornos dos fenômenos psicopatológicos, nos quais o real se entrelaça com o imaginário.

Nos capítulos dedicados à pesquisa, Virgínia Moreira volta ao campo da psicopatologia, apontando a perspectiva crítica do filósofo francês Maurice MerleauPonty como um avanço em relação à proposta fenomenológica original de Edmund Husserl, pois já não busca essências, e sim o significado da experiência vivida. Portanto, o pesquisador deve assumir sua subjetividade mundana, evitando uma suposta neutralidade científica. Em um dos capítulos, publicado em coautoria com o pesquisador Francisco Silva Cavalcante Jr., dedica-se à discussão da articulação do método fenomenológico mundano com a etnografia e a antropologia da experiência. Em dois outros capítulos, descreve sua experiência concreta com pesquisa transcultural: no primeiro, investiga o significado da experiência vivida da depressão no Brasil, no Chile e nos Estados Unidos, relacionando-o ao modo de vida dos pacientes nessas diferentes culturas; no segundo, em coautoria com 
o colega Georges Boris, analisa a vivência do corpo na esquizofrenia no Brasil e no Chile.

Noutro capítulo, com Célio Freire, Virgínia Moreira questiona, baseada no pensamento de Emmanuel Lévinas, se a depressão, doença da moda, não está mais relacionada a uma sociedade plena de desafeto e de indiferença ao outro do que a uma desordem dos afetos, tal como é classificada pelos manuais de psiquiatria atuais. No capítulo com Anna Karynne Melo e Mara Chaves, discute as influências culturais e ideológicas da pós-modernidade sobre o mundo vivido dos pacientes borderline, analisando algumas características da cultura ocidental. Juntamente com David Sam, discute a complexa relação entre cultura e doença mental, destacando sua mútua constituição e denunciando nosso limitado conhecimento a seu respeito, em parte decorrente da adoção do modelo biomédico.

Finalmente, no último capítulo, Virgínia Moreira desenvolve a ideia de que a psicopatologia se constitui mutuamente com a ecologia, pois faz parte dos seus múltiplos contornos, destacando que o reconhecimento da sua estreita ligação pode ser um passo importante na superação da epidemia de doenças mentais que assola o mundo contemporâneo.

Instigante, inquietante, questionador e ousado, o texto de Virgínia Moreira, portanto, serve não apenas aos profissionais psi, mas a todos que se preocupam com os (des) caminhos deste estranho mundo vivido por todos nós.

\section{Georges Daniel Janja Bloc Boris}

Psicólogo; mestre em educação e doutor em sociologia pela Universidade Federal do Ceará (Fortaleza, CE, Brasil); professor titular vinculado aos Programas de Pós-Graduação e de Graduação da Universidade de Fortaleza (Fortaleza, CE, Brasil); coordenador do Núcleo de Estudos das Relações de Gênero - NUGEN e do Núcleo de Pesquisas e Práticas em Processos Grupais - NUPEG, ambos ligados ao Laboratório de Psicopatologia e Psicoterapia Humanista-Fenomenológica Crítica - APHETO. Autor de Falas de homens: a construção da subjetividade masculina, lançado em 2002, pelo convênio Annablume/Secretaria da Cultura e Desporto do Estado do Ceará, Brasil.

Rua Pereira Filgueiras, 1985

60160-150 Fortaleza, CE, Brasil

e-mail: geoboris@uol.com.br

geoboris@unifor.br.

Rev. Latinoam. Psicopat. Fund., São Paulo, v. 13, n. 1, p. 137-139, março 2010 